\title{
Evaluation of Unknown Tube Well Depth Using Electrical Resistivity Method
}

\author{
Mohd Hazreek Zainal Abidin ${ }^{1,2, *}$, Aziman Madun ${ }^{1,2}$, Saiful Azhar Ahmad Tajudin ${ }^{1,2}$, \\ Mohamad Faizal Tajul Baharuddin ${ }^{1,2}$, Mohd Fairus Yusof $^{1,2}$, Muhammad Nizam Zakaria ${ }^{1,2}$, \\ Siti Nazahiyah Rahmat ${ }^{1}$ \\ ${ }^{1}$ Faculty of Civil and Environmental Engineering, Universiti Tun Hussein Onn Malaysia, 86400 Batu \\ Pahat Johor, Malaysia \\ ${ }^{2}$ Research Center for Soft Soil, Universiti Tun Hussein Onn Malaysia, 86400Batu Pahat Johor, \\ Malaysia
}

\begin{abstract}
Electrical resistivity method has increasingly adopted in engineering, environmental, mining and archaeological studies. Systematic and proper studies of unknown civil engineering structure evaluation particularly on tube well depth was rarely being established. Conventionally, camera test or string with weight approach has been used to evaluate unknown tube well depth thus exposed to several restriction due to its expensive and time consuming. Hence, this study focused on evaluation of unknown tube well depth using indirect test with particular reference to electrical resistivity method (ERM).A single spread line of electrical resistivity survey was performed using ABEM SAS 4000 equipment set based on Wenner and Pole-dipole array in line with the tube well position. Electrical resistivity raw data was processed using RES2DINV software producing electrical resistivity tomography (ERT) of the subsurface profile studied. Then, electrical resistivity value (ERV) obtained from RES2DINV analyses (ERT) was extracted and analysed using plotted graph (depth versus ERV) specifically at tube well position based on electrical resistivity spread line performed. It was found that both array have shown some good similarity results in term of tube well depth $(20 \mathrm{~m})$ thus able to verify the result interpreted. Both array have shown some good similarity of ERV representing groundwater (ERV $=10-100$ $\Omega \mathrm{m})$ and soil with water (ERV $>100 \Omega \mathrm{m}$ ) at depth of $0-20 \mathrm{~m}$ and $>20 \mathrm{~m}$ respectively. All those interpretation have shown good agreement based on verification thru established ERV of earth materials references, geological map and nearest available boreholes data. Hence, this study has shown that the application of ERM was applicable in evaluation of unknown tube well depth which efficient in term of cost, time and environmental sustainable.
\end{abstract}

* Corresponding author: hazreek@uthm.edu.my 


\section{Introduction}

Civil engineering subsurface mapping involve several sub-disciplines including environmental engineering, geotechnical engineering, earthquake engineering, water resources engineering, wastewater engineering and construction engineering. Several civil engineering underground structure (e.g. tube well, foundation, subsoil drain, etc.) was commonly being investigated due to forensic assessment. Common forensic assessment involve the investigation related to unknown or failure structure. In other words, forensic assessment is the investigation of materials, products, structures or components that lost, fail or do not operate or function as intended, which may cause some negative impact afterward. Forensic engineering normally investigate and collect data related to the materials, products, structures or components that lost or failed such as inspections, collecting evidence, measurements, developing models, obtaining prototype products, and performing experiments.

A tube well is a type of water well with specific design which being bored into an underground aquifer. The main purpose of tube well is to extract groundwater for several application in domestic and industrial sector such as agriculture, aquaculture, livestock, factory, mining, etc. From past experienced, proper and systematic forensic studies related to unknown tube well depth identification was rarely established. Unknown tube well depth was commonly occurred due to the long abandon project or loss of record. Conventional approach to measure unknown tube well depth was commonly based on informal method particularly by string and weight to measure the well depth. his approach may expose for some argument due to its efficiency of result accuracy and reliability.

Nowadays, geophysical method has increasingly adopted in most of the subsurface profile mapping due to its efficiency in term of cost, time and data coverage. Moreover, the nature of indirect or surface technique (non-destructive method) used in geophysical data acquisition has contribute benefit with our environment particularly in reducing site damageability thus sustainable to our environment. However, the successful performance of geophysical method may relative to fundamental physical constraint (e.g. penetration, resolution, and signal to-noise ratio) [1-2].Geophysical method used the physics concept to characterize the subsurface profile. Common, physics properties used including resistivity, wave, density, magnetic susceptibility, etc. Then, specific geophysical equipment has been invented based on those physics properties (e.g. electrical resistivity, seismic, ground penetrating radar, gravity, magnetic, etc.).Geophysical method has widely being applied in several areas related to forensic assessment [3-6], environmental [7-11], engineering [1214], mining [15-17] and archaeological [18-20] studies .Consequently, this study was performed to establish the application of electrical resistivity method for unknown tube well depth evaluation which being verified using established properties of earth materials resistivity, geological map and borehole data.

\section{Methodology}

\subsection{Study area and geological setting}

This study was performed at hydro-meteorology station in UTHM, Johor as shown in Fig.1. Generally, site topography was flat which surrounded by private factory, university buildings (laboratory, class and offices) and golf course. General geology of Peninsular Malaysia area has been well documented [21]. Based on geological map shown in Fig.2, this study area consists of unconsolidated deposits from clay and silt (marine). In general, the present of this type of materials will exhibits soft soil phenomenon due to its high water 
content derived from high water table of lowland areas. Moreover, high rainfall intensity which was commonly occurred in tropical climate country as Malaysia also has contribute to the increment of water table thus promoting to the soft soil phenomenon in study areas. Previous borehole results obtained from PPH, UTHM also found that this area consist of thick clay and silt [22] thus suitable for groundwater carriage and storage. However, fine particle of soils such as clay and silt may associate with low hydraulic conductivity which may influence the effectiveness of groundwater recharge and quality extracted from the existing tube well. Hence, several testing such as pumping and water quality test need to be performed thoroughly in order to obtain comprehensive results and conclusion. Based on site observations, soft soil condition related to wet clay and silt geomaterials can easily found in study area. These evident can be used as an indicator regarding the composition of subsurface profile that possibly consist of homogeneous soft soil geomaterials.

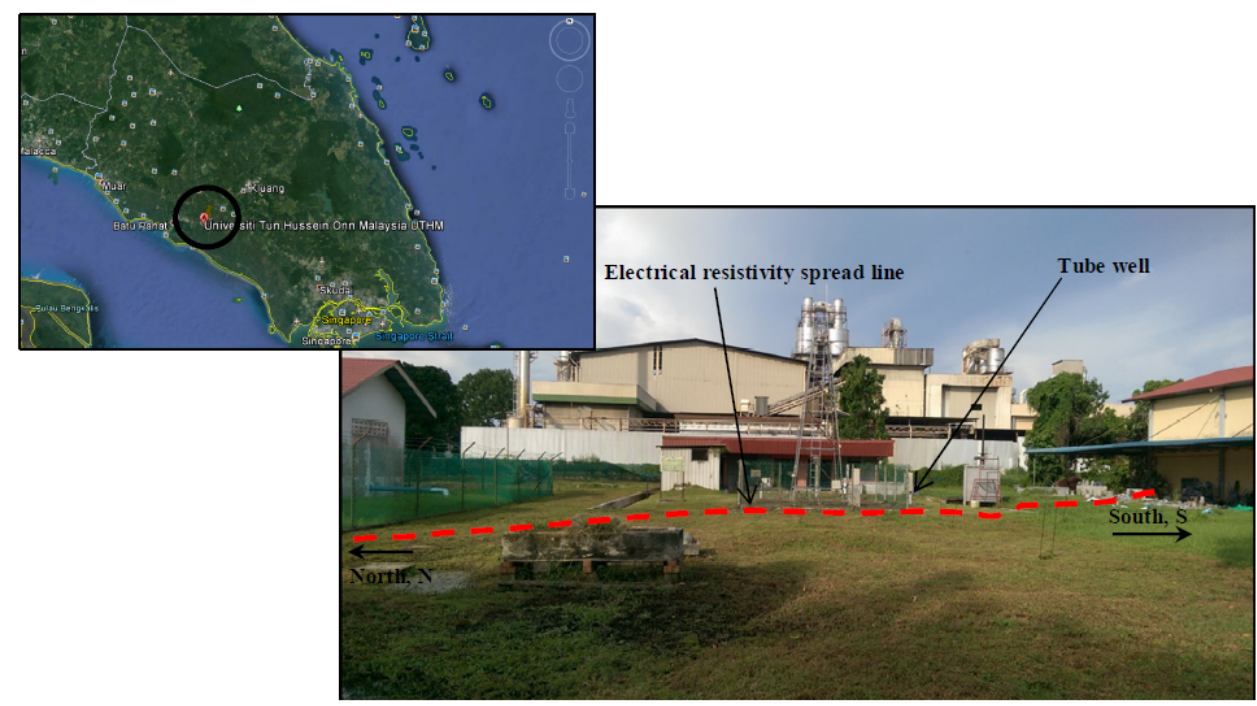

Fig. 1. Study area

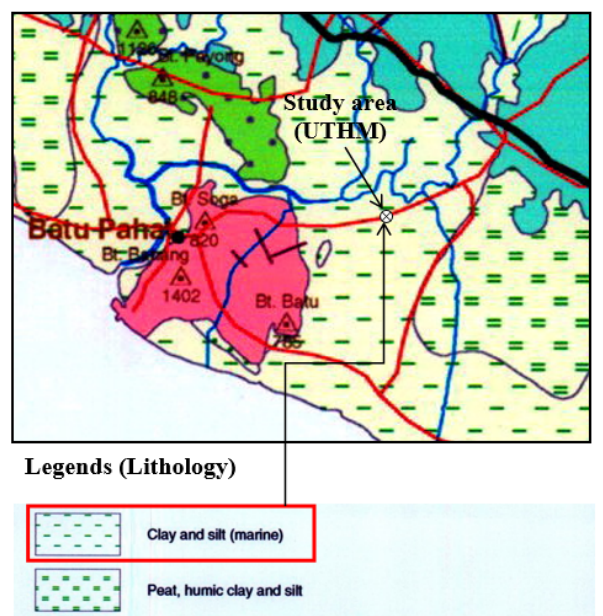

Fig. 2. Geology of study area [21] 


\subsection{Data acquisition and processing}

Electrical resistivity imaging (ERI) was performed using the ABEM Terrameter SAS 4000, combined with ES 10-64 electrode selector. A fixed single line of electrical resistivity survey was performed across the target of interest (tube well unknown depth) zone. Testing configuration was based on Wenner and Pole-dipole array using four (4) resistivity land cables, sixty one (61) numbers of inline electrode plus one remote electrode and sixty five (65) numbers of jumper cable. Equal electrode spacing of $3.0 \mathrm{~m}$ was used for all 61 electrodes producing total electrical resistivity spread line length of $240 \mathrm{~m}$. Field arrangement and alignment of spread line of the electrical resistivity imaging was given in Fig. 3 and 4 respectively. Wenner and Pole-dipole array was performed in this study due to verification purposes representing low and high intensity of electrical resistivity data. Furthermore, Pole-dipole array was able to provide greater depth of subsurface profiles within limited spaced area during the resistivity data acquisition. Raw data obtained from data acquisition was processed using commercialize RES2DINV software of [23] to provide an inverse model that approximates the actual subsurface structure. The inversion algorithm of RES2DINV was used to process the data, as proposed by [24] in order to obtain the 2-D resistivity section (Electrical resistivity tomography, ERT). Finally, electrical resistivity value (ERV) obtained from RES2DINV analysis was extracted and plotted with depth specifically at horizontal distance (x) of $121.5 \mathrm{~m}$ (based on tube well position from the first electrode within the spread line performed in Northsouth direction). Schematic diagram explaining the extraction of ERV from ERT was given in Fig. 5.

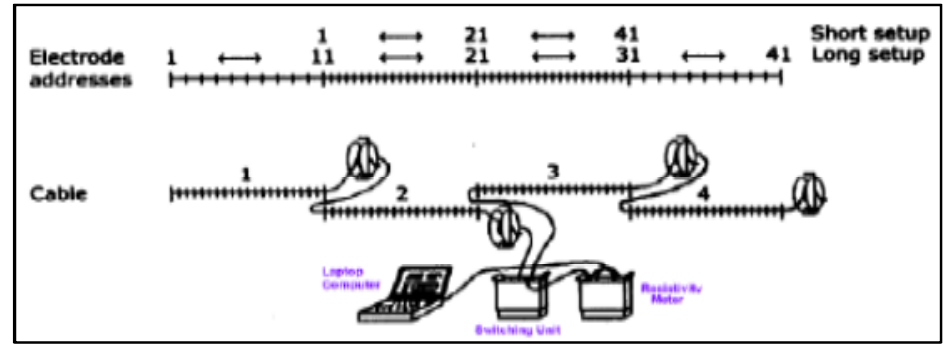

Fig. 3. Electrical resistivity imaging (ERI) field arrangement performed at hydro-meteorology station, UTHM Johor [25]

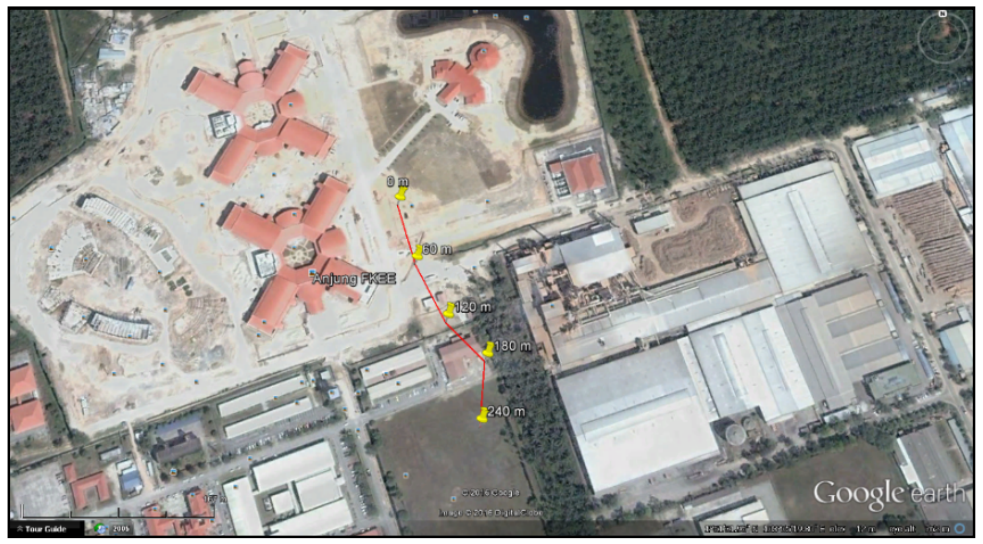

Fig. 4. Alignment (Northsouth) of electrical resistivity (spread lines) performed at hydro-meteorology station, UTHM Johor 


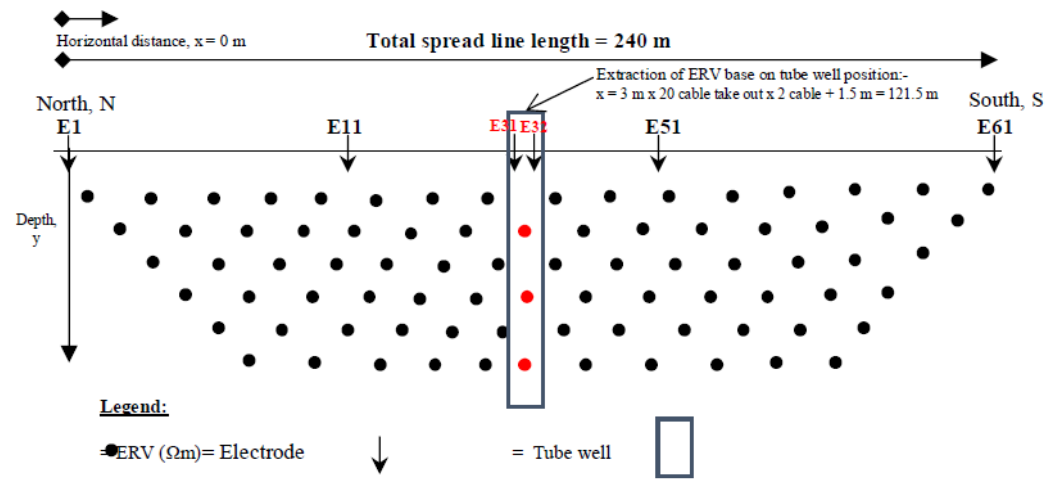

Fig. 5. Extraction of ERV from ERT pseudosection

\section{Results and discussions}

Basically, electrical resistivity value (ERV) was determined by measuring the potential difference at points on the ground surface which caused the propagation of direct current through the subsurface [26]. Traditionally, four (4) electrodes related to two (2) outer current electrodes and two (2) inner electrodes representing current and potential electrode was used to measure the resistivity of earth materials as shown in Fig. 6. Resistivity of earth material will be plotted at the middle of both potential electrode (between P1 and P2) after current being injected thru the subsurface profile using current electrode. This traditional four electrode system of resistivity technique was popularly known as vertical electrical sounding (VES) and constant separation traversing (CST) subjected to depth and lateral resistivity measurement. The limitation of traditional VES and CST technique was due to time consuming and limited data coverage (1-D) especially when working in a large and difficult study area. Nowadays, electrical resistivity technique has evolved due to the rapid development of high technology and sophisticated innovative equipment. The development of high technology and sophisticated electronics devices has invent the electrical resistivity method from VES and CST to imaging technique. Electrical resistivity imaging (ERI) technique permit to performed the data acquisition (field measurement) of resistivity method in two dimensional (2-D) and three dimensional (3-D) perspectives resulting an electrical resistivity tomography (ERT). Basic configuration of electrical resistivity imaging (ERI) was given in Fig. 7. Hence, field measurement was able to be performed quickly, low cost, large data coverage and sustainable to study area.

All results of resistivity method was presented based on Wenner array (Table 1, Fig. 8 and 10) and Pole-dipole array (Table 2, Fig. 9 and 11). ERV obtained in Table 1 and 2 was originally extracted from ERT based on Fig. 10 and 11 as explained in section 2.2. Variation of ERV with depth obtained at this particular point $(\mathrm{x}=121.5 \mathrm{~m})$ will be an indicator of the tube well depth identification. Then, ERV data series from Table 1 and 2 was plotted with depth in order to analysed and conclude depth of tube well studied (Fig. 10 and 11). According to Fig. 10 and 11, it was found that length of tube well was approximately interpreted as $20 \mathrm{~m}$ depth from the ground level. Fig. 8 and 10 has demonstrate clearly that the ERV from depth of 0 to $20 \mathrm{~m}$ was varied around $1-100 \Omega \mathrm{m}$ representing groundwater. Then, ERV starts to increase at depth of $20 \mathrm{~m}$ and over by $>100$ $\Omega \mathrm{m}$ representing soil with water. In addition, ERT given in Figure 10 and 11 has shown that the subsurface profile compose of thick and homogeneous of soft layer representing marine clay and silt. Stiffness of soil profile has been dominated by weak soil which gradually increased of its stiffness with depth. From soil mineral composition perspectives, 
fine particles such as clayey and silty soil experience higher minerals with particular reference to kaolinite, illite, montmorillonite and vermiculite which allows the ease of the current propagation in the soil tested thus produces low resistivity value in contrast with coarse soil (sand and gravel). Furthermore as reported by Abidin et al. [5], resistivity data exhibits a low value for a fine soil such as clayey and silty while the coarser soil such as sand and gravel will produce a higher resistivity value. This ERT interpretation was verified thru UTHM's borehole report [22] which stated that soil profile in UTHM consist of thick (>30 m depth) and homogeneous fine soil (clay and silt).

Geophysical methods are incapable to stand alone in order to provide solutions to any particular problems [27-28]. Hence, strong verification from established data was important to support the electrical resistivity result interpreted. Previous original document of tube well studied (detail drawing) was missing and still in searching progress since this project has been abandon several years ago. Moreover, the original researcher leader of this tube well project was already resign and move to another agency sector. Since there are no other supportive information or data to verify above finding, those tube well depth interpretation was verified thru established ERV references based on ERV of groundwater and soil. Moreover, two (2) types of array (Wenner and Schlumberger) performed in this study was found to be in good agreement (consistency of ERV vs Depth given in Fig. 12 and 14) thus able to verify the result reliability interpreted. Based on Table 1 and 2, dissimilarity of ERV was obtained due to the different array used. Dissimilarity of ERV relative to different array performed was commonly occurred even it has been performed exactly at same particular spread line position/alignment/location together with similar environment and ground condition. One of the main factors contributed to this phenomenon was due to the geometry factor, K derived from different types of array established [29-30]. Hence, the value of ERV calculated was different based on $\mathrm{K}$ factor applied in every measurement due to its dissimilarity of current propagation for ERV determination. Geometry factor, K describes the geometry of the electrode configuration used in data acquisition. Apparent resistivity ( $\rho$ a) is ERV estimated based on half-pace geometry assumption which refers to the field ERV. According to [31], apparent resistivity will be equal to the true resistivity provided the current and configuration was applied over the homogeneous isotropic ground. Field ERV was determined using Wenner and Pole-dipole array with a geometry factor as given in final Equation 1 and 2 which is derived from basic Equation 3 and 4 . Wenner and Poledipole geometry factor, $\mathrm{K}$ used in this study was derived from Equation 4 based on basic four electrode system of measurement. The schematic diagram of field resistivity configuration used was given in Fig.12 and Fig. 13 while the schematic diagram for the four electrode system is given in Fig. 14.

Electrical resistivity for groundwater and clays was varied from $10-100 \Omega \mathrm{m}$ [31]. Meanwhile, ERV for clayey and silty soil was varied from $1-100 \Omega \mathrm{m}$ [31] and $200-500$ $\Omega \mathrm{m}$ [32] respectively subjected to several factors such as degree of saturation, basic physical properties of soil, salt concentration, etc. The fluctuation of ERV at tube well and soil layer may influenced by variation of physical and chemical content present within the subsurface profile studied. As reported by [21], study area composed of clay and silt from marine environment thus may influenced the consistency of ERV due to the possibility of ancient seawater trap. Samsudin et al. [33], have reported that ancient seawater that was trap within the sediment long time ago may influence the groundwater characteristic. Resistivity value was highly influenced by pore fluid and grain matrix of geomaterials [34]. According to Abidin et al [35-38], ERV of geomaterials was largely influenced by the variations of basic physical properties of soil such as grain size fraction, moisture content and density. As reported by [39], a soil's ERV generally varies inversely proportional to the water content and dissolved ion concentration as clayey soil exhibit high dissolved ion concentration, wet clayey soils have lowest resistivity of all soil materials while coarse, dry 
sand and gravel deposits and massive bedded and hard bedrocks have the highest ERV. Furthermore a decrease of ERV was results from an increase of metal ions or inorganic elements in geomaterials [40].

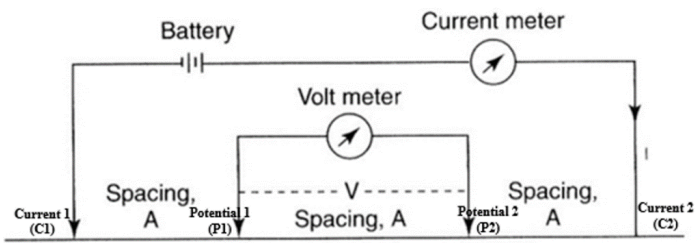

Fig. 6. Basic configuration of VES and CST in electrical resistivity method [26]

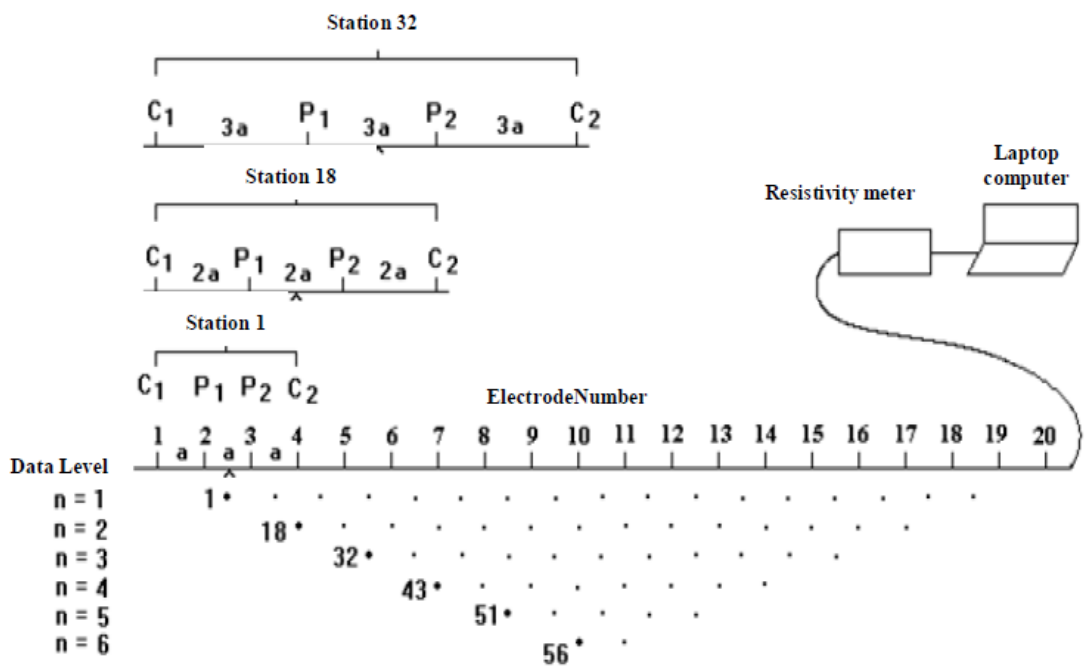

Fig. 7. Basic configuration of 2-D ERI in electrical resistivity method and the sequence of measurements used to build up a pseudosection [41]

Table 1. ERV data series at tube well position (Wenner array).

\begin{tabular}{|c|c|}
\hline \multicolumn{2}{|c|}{ Wenner array $(\mathrm{x}=121.5 \mathrm{~m})$} \\
\hline Depth $(\mathrm{m})$ & ERV $($ Ohm.m $)$ \\
\hline 0.75 & 6.285 \\
\hline 2.25 & 6.285 \\
\hline 3.825 & 6.466 \\
\hline 5.557 & 8.309 \\
\hline 7.463 & 9.103 \\
\hline 9.56 & 10.077 \\
\hline 11.866 & 14.115 \\
\hline 14.402 & 28.958 \\
\hline 17.192 & 56.416 \\
\hline 20.261 & 87.305 \\
\hline 23.638 & 108.04 \\
\hline 27.351 & 117.92 \\
\hline 31.437 & 121.72 \\
\hline 40.873 & 124.58 \\
\hline 46.311 & 309.84 \\
\hline
\end{tabular}


Table 2. ERV data series at tube well position (Pole-dipole array).

\begin{tabular}{|c|c|}
\hline \multicolumn{2}{|c|}{ Pole-dipole array $(\mathrm{x}=121.5 \mathrm{~m})$} \\
\hline Depth $(\mathrm{m})$ & ERV $($ Ohm.m $)$ \\
\hline 0.75 & 63.354 \\
\hline 2.25 & 38.039 \\
\hline 3.825 & 32.758 \\
\hline 5.557 & 31.728 \\
\hline 7.463 & 6.683 \\
\hline 9.56 & 1.838 \\
\hline 11.866 & 1.838 \\
\hline 14.402 & 19.362 \\
\hline 17.192 & 108.73 \\
\hline 20.261 & 187.8 \\
\hline 23.638 & 204.11 \\
\hline 27.351 & 205.47 \\
\hline 31.437 & 206.34 \\
\hline 35.93 & 207.03 \\
\hline 40.873 & 207.64 \\
\hline 46.311 & 208.16 \\
\hline 58.871 & 209.03 \\
\hline 66.108 & 209.37 \\
\hline & \\
\hline
\end{tabular}




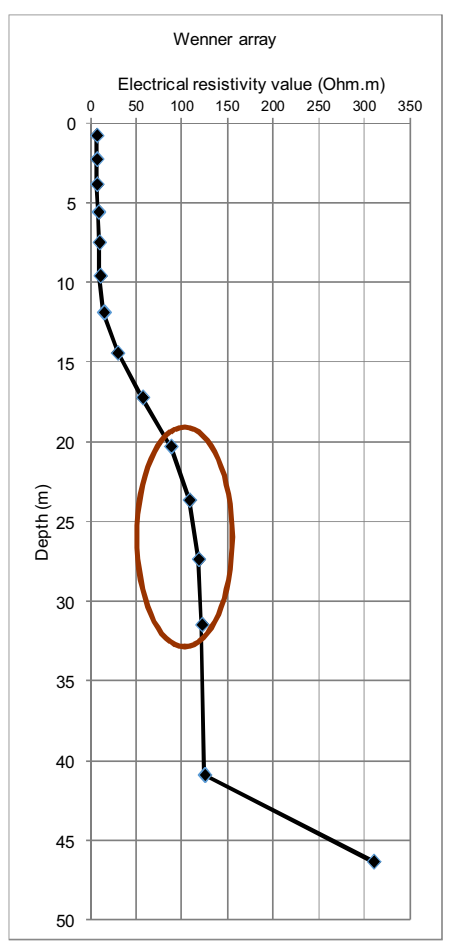

Fig. 8. ERV vs depth (Wenner array)

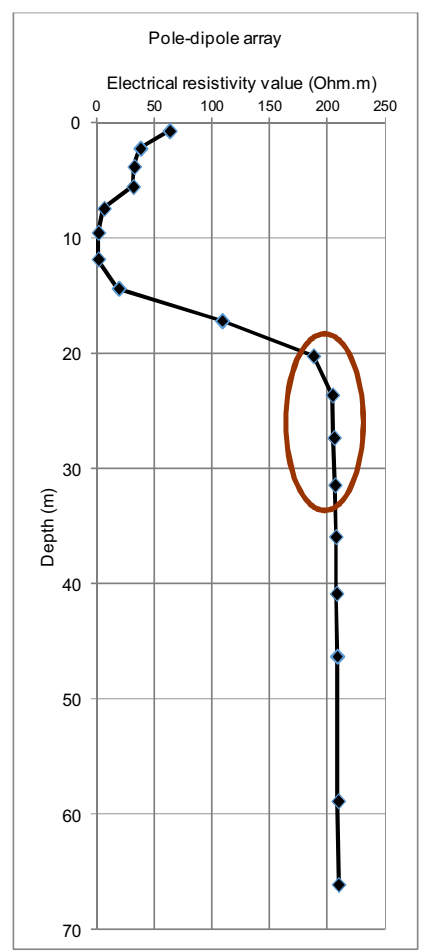

Fig. 9. ERV vs depth (Pole-dipole array)

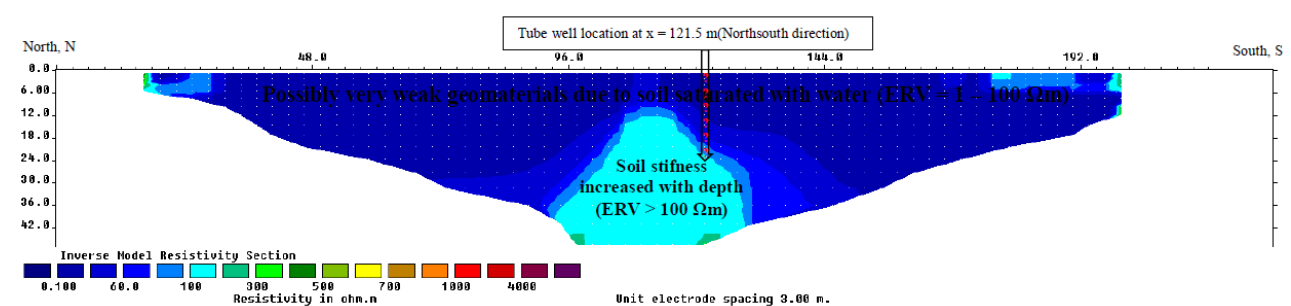

Fig.10. Electrical resistivity tomography (ERT) based on Wenner array (Northsouth direction)

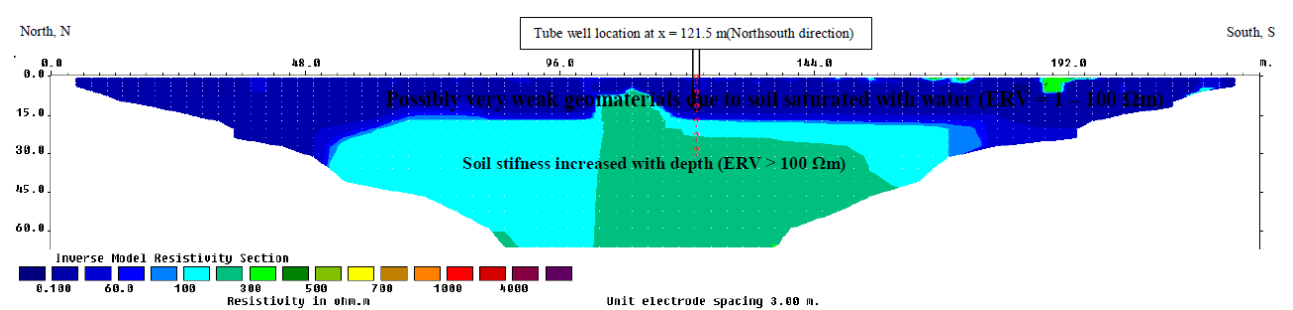

Fig. 11. Electrical resistivity tomography (ERT) based on Pole-dipole array (Northsouth direction)

$$
\rho_{a}=2 \pi a^{*} R
$$

where $R$ is a resistance term given by $R=\Delta V / I$ 


$$
\rho_{a}=((2 \pi a b) /(b-a)) * R
$$

where $\mathrm{R}$ is a resistance term given by $\mathrm{R}=\Delta \mathrm{V} / \mathrm{I}$

$$
\rho_{a}=K * R
$$

where $\mathrm{R}$ is a resistance term given by $\mathrm{R}=\Delta \mathrm{V} / \mathrm{I}, \mathrm{K}$ is geometry factor based on pole-dipole electrode configuration

$$
\left.\rho_{a}=((2 \pi \Delta V) / I)\right) *((1 /(1 / r 1-1 / r 2)-(1 / r 3-1 / r 4))
$$

where $K=((1 /(1 / r 1-1 / r 2)-(1 / r 3-1 / r 4))$

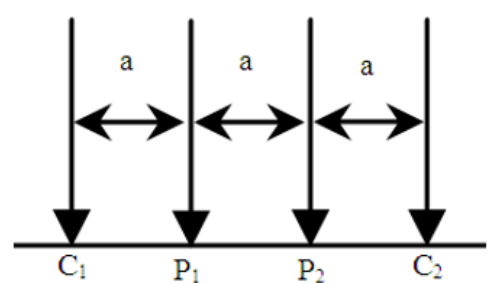

Fig. 12. Wenner electrode array arrangement

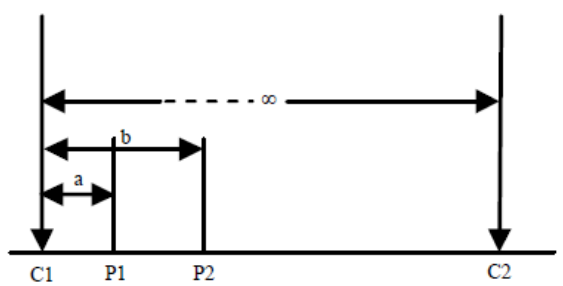

Fig. 13. Pole-dipole electrode array arrangement

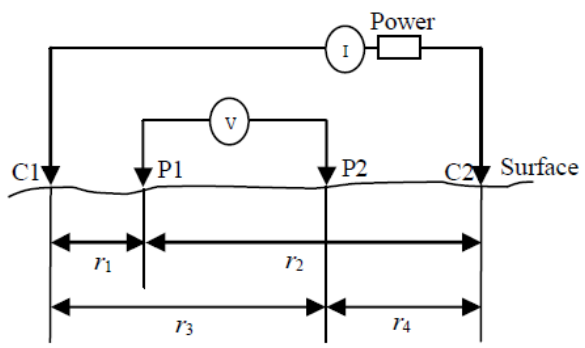

Fig. 14. Four electrodes arrangement on the surface of homogeneous isotropic ground of resistivity

\section{Conclusion}

The problematic of unknown tube well depth $(20 \mathrm{~m})$ was successfully being investigated using electrical resistivity method. The geometry and electrical resistivity anomaly distribution has been determined by analyzing electrical resistivity data obtained along the tube well location and the result has shown a good correlation based on previous references. This finding has proved that this approach was applicable to investigate the tube well depth particularly involving unknown tube well depth. Electrical resistivity method was successfully mapped the ground profile which able to extend the surface information observed during the physical mapping. The geometry of tube well can be easily recognized based on variations of ERV obtained. This geophysical method is suitable for our 
sustainable ground investigation since it can reduce time, money and compliment others conventional method. The application of ERI in conjunction with other records (borehole data, geological information, established resistivity values of geomaterials, etc) was applicable being applied to the evaluation of the unknown tube well depth due to its ability to differentiate properties of earth materials.

This work was funded by Universiti Tun Hussein Onn Malaysia (IGSP of Vote U258 and FRGS of Vote 1455). Many thank are due to all research members for their tremendous work and cooperation.

\section{References}

[1] H.J. Mauritsch, W. Seiberl, R. Arndt, A. Römer, K. Schneiderbauer, G. P. Sendlhofer, Geophysical investigations of large landslides in the Carnic Region of Southern Austria, Engineering Geology, 56, 373-388 (2000)

[2] D.M. McCann, A. Forster, Reconnaissance geophysical methods in landslide investigations, Engineering Geology, 29, 59-78 (1990)

[3] Z.A.M. Hazreek, A.T.S. Azhar, M. Aziman, S.M.S.A. Fauzan, J.M. Ikhwan, M.A.N. Aishah, Forensic assessment on ground instability using electrical resistivity imaging (ERI), The 2nd Int. Conf. on Rheology and Modelling of Materials, Miskolc-Lillafüred, Hungary, (2015)

[4] M.H. Z. Abidin, R. Saad, F. Ahmad, D.C. Wijeyesekera, M.F.T. Baharuddin, Seismic refraction investigation on near surface landslides at the Kundasang area in Sabah, Malaysia, Procedia Engineering, 50, 516-531 (2012)

[5] M.H.Z. Abidin, R. Saad, F. Ahmad, D.C. Wijeyesekera, M.F.T. Baharuddin, Integral analysis of geoelectrical (resistivity) and geotechnical (SPT) data in slope stability assessment, Academic J. of Science, 1(2), 305-316 (2012)

[6] M.H.Z. Abidin, M.F.. Baharuddin, A.F. Kamarudin, Application of geoelectrical method in subsurface profile forensic study, Proc. of Malaysian Technical Universities Conf. on Engineering and Technology, Melaka, Malaysia, (2010)

[7] A. Abdulrahman, M. Nawawi, R. Saad, A.S. Abu-Rizaiza, M.S. Yusoff, A.E. Khalil, K.S. Ishola, Characterization of active and closed landfill sites using 2D resistivity/IP imaging: Case studies in Penang, Malaysia, Environmental Earth Sciences,75, 347, (2016)

[8] K. Parial, A. Biswas, S. Agrahari, S.P. Sharma, D. Sengupta, Identification of contaminated zones using direct current resistivity surveys in and around ash ponds near Kolaghat Thermal Power Plant, West Bengal, India, Int. J. of Geology \& Earth Sciences, 1(2), 55-64 (2015)

[9] M.F.T. Baharuddin, A.R. Othman, S. Taib, R. Hashim, M.H. Zainal Abidin, M.A. Radzuan, Evaluating freshwater lens morphology affected by seawater intrusion using chemistry-resistivity integrated technique: A case study of two different land covers in Carey Island, Malaysia, Environmental Earth Sciences, 69, (2013)

[10] M.F.T. Baharuddin, S. Taib, R. Hashim, M.H. Z. Abidin, Assessment of seawater intrusion to the agricultural sustainability at the coastal area of Carey Island, Selangor, Malaysia, Arabian J. of Geosciences, 6, 3909-3928 (2013)

[11] M.H. Loke, Electrical imaging surveys for environmental and engineering Studies, A Practical Guide to 2-D and 3-D Surveys, 1-67 (1999)

[12]R. Arjwech, M. E. Everett, Application of 2D Electrical Resistivity Tomography to Engineering Projects: Three Case Studies, Songklanakarin J. Science and Technology, 37(6), 675-681, (2015) 
[13]A. Madun, I. Jefferson, K.Y. Foo, D.N. Chapman, M.G. Culshaw, P.R. Atkins, Characterization and quality control of stone columns using surface wave testing, Canadian Geotechnical J., 49, 1357-1368 (2012)

[14]R. Saad, N.M. Muztaza, E.T. Mohamad, The 2D electrical resistivity tomography (ERT) study for civil and geotechnical engineering purposes, Electronic J. of Geotechechnical Engineering, 16, 1537-1545 (2011)

[15]M. Zarrocaa, R. Linaresa, P.C. Velásquez-Lópezb, C. Roquéc, R. Rodríguezd, Application of electrical resistivity imaging (ERI) to a tailings dam project for artisanal and small-scale gold mining in Zaruma-Portovelo, Ecuador, J. of Applied Geophysics, 113, 103-113 (2015)

[16] S.K. Nasab , A. Hojat, A. Kamkar-Rouhani, H.A. Javar, S. Maknooni, Successful use of geoelectrical surveys in area 3 of the Gol-e-Gohar Iron Ore Mine, Iran, Mine Water and the Environment, 30(3), 208-215 (2011)

[17] M.N. Tijani, O.O. Osinowo, O. Ogedengbe, Mapping of sub-surface fracture systems using integrated electrical resistivity profiling and VLF-EM methods: A case study of suspected gold mineralization, Materials and Geoenvironment, 56(4), 415-436 (2009)

[18]J.M. Terrón, V. Mayoral, J.A Salgado, F.A. Galea, V.H.C. Odriozola, P. Mateos, A. Pizzo, Use of soil apparent electrical resistivity contact sensors for the extensive study of archaeological sites, Archaeological Prospection, 22(4), 269-281 (2015)

[19]A. Hawamdeh, R. Jaradat, Z. Alsaad, Integrated application of geophysical methods for investigation of the Al-Berktain archaeological site in the City of Jerash, Jordan, Environmental Earth Sciences,73(7), 3665-3674 (2015)

[20]M. Marchetti, V. Sapia, A. Garello, D.D. Rita, A. Venuti, Geology and geophysics at the Archeological Park of Vulci (Central Italy), Annals of Geophysics, 57, (2014)

[21]M.G.D. Malaysia, Geological Map of Peninsular Malaysia, 8th Ed.,(1985)

[22]T. Gerudi, Cadangan Pembinaan Kolej Universiti Tun Hussein Onn, Laporan Penyiasatan Tapak, (2002)

[23] M.H. Loke, I. Acworth, T Dahlin, A comparison of smooth and blocky inversion methods 2-D electrical imaging surveys, Exploration Geophysics, 34(3), 182-187 (2013)

[24]M.H. Loke, R.D. Barker, Rapid least squares inversion of apparent resistivity pseudosection using a Quasi-Newton Method, Geophysics Prospective,44(1), 131- 152 (1996)

[25] ABEM, Terrameter SAS 4000/SAS 1000 Instruction Manual, ABEM Instrument AB, Sweden, (2010)

[26]H.R. Burger, A.F. Sheehan, C.H. Jones, Introduction to Applied Geophysics , W.W. Norton \& Company, (2006)

[27] S. G. C. Fraiha, J. B. C. Silva, Factor analysis of ambiguity in geophysics, Geophysics., 59(7), 1083-1091(1994)

[28]R.C.Benson, L. Yuhr, R.D. Kaufmann, Some considerations for selection and successful application of surface geophysical methods, Proc. the 3rd Int. Conf. on Applied Geophysics, Orlando, Florida (2003)

[29] M.H.Z. Abidin, R. Saad, D.C. Wijeyesekera, F. Ahmad, N.A. Ismail, the influence of electrical resistivity array on its soil electrical resistivity value, Applied Mechanics and Materials, 510, 185-192 (2014)

[30] M.H.Z. Abidin, R. Saad, D.C. Wijeyesekera, F. Ahmad, The influence of electrical resistivity array on its soil electrical resistivity value, Electronic J. of Geotechnical Engineering, 18, 5643-5653 (2014)

[31]W.M. Telford, L.P. Geldart, R.E. Sheriff, Applied Geophysics, Cambridge University Press, Cambridge, (1990) 
[32]T.S. Lee, Slope Stability and Stabilization Methods: Geologic Site Investigation in chapter 4, John Wiley \& Sons. Inc., (2002)

[33] A.R. Samsudin, A. Haryono, U. Hamzah, A.G. Rafek, Salinity mapping of coastal groundwater aquifers using hydrogeochemical and geophysical methods: A case study from North Kelantan, Malaysia, Environmental Geology, 55(8), 1737-1743 (2008)

[34]D.H. Griffiths, R.F. King, Applied Geophysics for Geologist and Engineers: The Element of Geophysical Prospecting, Pergamon Press, (1981)

[35]Z.A.M. Hazreek, S. Rosli, W.D. Chitral, F. Ahmad, A.T.S. Azhar, M. Aziman, B. Ismail, Soil identification using field electrical resistivity method, J. of Physics: Conf. Series, 622, 1, (2015)

[36]Z.A.M. Hazreek, M. Aziman, A.T.S. Azhar, F. Fauziah, S. Rosli, The behaviour of laboratory soil electrical resistivity value under basic soil properties influences, IOP Conf. Series: Earth and Environmental Sciences, 23, 1, (2015)

[37]Z.A.M. Hazreek, F. Fauziah, D.C. Wijeyesekera, R. Saad, The influence of basic physical properties of soil on its electrical resistivity value under loose and dense condition, J. of Physics: Conf. Series, 495, 1, (2014)

[38] M.H.Z. Abidin, R. Saad, F. Ahmad, D.C. Wijeyesekera, M.F.T. Baharuddin, Correlation analysis between field electrical resistivity value (ERV) and basic geotechnical properties (BGP), Soil Mechanics and Foundation Engineering, 51(3), 117-125 (2014)

[39]C. Liu, J.B. Evett, Soils and Foundation, Pearson Prentice Hall, (2008)

[40] Y. Jung, Y. Lee, H. Ha, application of electrical resistivity imaging techniques to civil and environmental problems, Use of Geophysical Methods in Construction, (2000)

[41]R.D. Barker, Electrical imaging and its application in engineering investigations, Geological Society, London, Engineering Geology Special Publications, 12, 3743(1997) 